\title{
Reflections on the role of medical staff governor in a foundation trust
}

\author{
Sarah Pearce
}

\begin{abstract}
A foundation trust will usually elect one or more medical staff representatives to the board of governors. This person is likely to be the most influential member of that board through knowledge, experience and self-confidence. This paper outlines the experience of one medical staff governor and some of the ways in which it is possible to support colleagues as well as management. Most importantly the role can have a crucial watchdog function when major financial pressures impinge on resources. The role is ideally suited to a senior physician with reduced clinical commitments. It repays the time and trouble invested.
\end{abstract}

\section{KEY WORDS: foundation trust, medical staff governor}

The County Durham and Darlington acute hospitals became a foundation trust (FT) four years ago. In an FT, the governors oversee the trust board and represent the voice of the community and stakeholders. Boards of governors are there to advise, support and be consulted. They appoint the non-executive directors (but not the chair who also chairs the board of governors) and can also remove them if sufficiently dissatisfied by their performance. ${ }^{1}$ They meet around four times a year and also set up a number of subcommittees, the exact functions of which can be decided by them.

The staff are stakeholders and constitute an important part of the community. The trust board devised the constitution in consultation with Monitor (the independent body that oversees FTs) and decreed that out of 37 governors, seven should represent staff constituencies. Only one of those would have the responsibility of representing 400 doctors in five hospitals. Other governors represented local communities. There were also governors appointed by stakeholder organisations, such as county council, universities and the primary care trust.

There was no serious competition for the post of medical staff governor. Some noted that the position was unpaid. The tendency also is for consultants to focus closely on their area of interest without necessarily feeling obliged to take on an organisational role. Many more colleagues were under pressure and felt that they had no time. I was within a few years of retirement and was reducing my commitments. I decided the role might provide interest and probably influence until I bowed out. I set myself a three-point agenda to:

- keep service to the community rather than governmentimposed targets at the top of my priorities

Sarah Pearce, retired consultant physician
- improve the poor relationship between staff and chief executive officer (CEO)

- raise morale.

This was ambitious but liked by my colleagues and I had ideas about how I could start to address these issues.

We called ourselves the 'governing council'. The executive directors were somewhat anxious about this new body and its potential to cause trouble. Their anxiety was reflected in that we were told at least three times that operational management was not our business, that the trust board carried the responsibility and that our right was only to be informed and consulted. I decided to sail as close to the wind as I could.

\section{Communicating with one's constituents}

It seemed that an essential first step would be to improve my contact with medical staff around the trust by occasional attendance at all the staff committees and by frequent emails (I developed an informal style, laced with occasional humour and emphatically non-managerial in tone. It was appreciated). It was also important to develop a mutually supportive relationship with the CEO and then use my new role as a bridge between him and consultant colleagues. The arrival of a new CEO provided the opportunity to do that and I found he was also glad to use me when relations between him and particular colleagues became strained. I regularly invited colleagues to inform me about any issue that concerned them and advised them when I was due to see the CEO for private meetings. He was willing to receive information from me on a non-attributable basis if necessary. Colleagues regularly responded and several came to me quite distressed about issues or frustrated at their inability to move an issue forward. Undue pressure on clinical service managers (perceived as bullying) became an issue - it seemed that they felt afraid to complain themselves and thus their consultant colleagues turned to me. I believe I was able to help in several cases. People generally were appreciative that they had an alternative route to the top without having to go through line managers. They perceived me as 'on our side' though in fact I saw myself as 'on the side of' the trust as a whole. It is not a 'trade union' role.

\section{The power to influence}

It was apparent that the medical staff governor was in a very important position because no other governor had equivalent understanding of the clinical issues combined with the 
confidence to speak out at governors' meetings and challenge the trust board or executives. I was promptly elected to chair the governors' strategy group and found that the executive developed a healthy respect for this body. To us fell the task of reviewing the annual plan and its forward extension. This proved to be largely a financial exercise which was important but dry for committee members whose interests were not primarily financial. In order to flesh out the finance we asked various clinical departments to present their difficulties to the committee. We were quickly accused of involving ourselves in 'operational management' but we made the case that we were examining weak points in implementation of a strategy and this had to be accepted. By putting an issue on the agenda (inevitably this was emergency care and acute medicine), asking for a report back and then raising it at the next meeting under 'matters arising' we could keep it on the agenda as long as we liked until we felt satisfied. The committee was enthralled by this tactic and we were genuinely challenging the executive.

\section{Improving morale}

There was a constant complaint of poor morale among medical staff. How could this be addressed? It seemed genuine. I suggested an 'innovation day' at which colleagues could present to managers and to each other, service improvements, research or developments of any sort of which they were proud or which they wanted to introduce. I found this idea was immediately accepted by management, was funded, was very successful and is now embedded as an annual event. It improved morale for those involved who enjoyed the fact that 'for once' managers were listening to clinicians with admiration. An annual staff dinner was re-instituted - it proved hard work to gather a worthwhile number of attendees but was so enjoyable that it has been repeated.

\section{Governor as whistleblower}

It became apparent that the medical staff governor has a huge responsibility to act as the whistleblower if indicated. Because people came to me with their problems I was in an excellent position to know where things were going wrong. Because of my responsibility to the trust I had to take up any serious issues and I did need to blow the whistle in one area where colleagues were not playing by the rules. That situation received top level attention before it would otherwise have done and is slowly improving. Worrying staffing levels in another department were flagged up to the governing council and addressed by the executive.
The watch dog function may be the most important part of the medical staff governor role especially in the current financial situation when financial pressures are a threat to quality and safety. A proactive medical staff governor could undoubtedly draw dramatic attention to problems such as those experienced at the Mid-Staffordshire Trust.

\section{Conclusion}

The role of medical staff representative on the board of governors of an FT has not had a high profile but has enormous potential and can be influential. Much good can be done by acting as a channel of communication between colleagues and senior management. One can influence and challenge the top management and, most importantly, can act as 'watchdog' and be in a position to blow a whistle to the CEO, chairman or board of governors if action is not taken.

The role was highly enjoyable, largely because it gave a new interest to my career at a time when I was otherwise winding down. I also enjoyed getting to know colleagues around the trust with whom I might not otherwise have communicated. By making sure I was well-informed and by playing strictly fair not toeing the party line for consultants but putting the trust's service to the community at the top of my list of priorities - I found my views were respected on all sides and influence grew with that. When I retired there was still no competition for the role but one senior and experienced person was attracted to the position and aimed to continue along the trail I had blazed.

This role is very appropriate for a senior physician approaching retirement and I commend it. An ability to be fairminded, network and communicate at every level is an advantage. Seniority is an asset. A younger physician with a full timetable might find it difficult, but not impossible, to give adequate time to the position. It is unpaid but could attract clinical excellence points or count as a supporting professional activity. It is certainly rewarding but, as is often the case, the reward is proportional to the time and effort invested.

\section{Reference}

1 Governors in NHS foundation trusts: what the law says you have to do. Monitor, 2010. www.monitor-nhsft.gov.uk/home/ourpublications/browse-category/guidance-foundation-trusts/reports/ guidance-governors/governor

Address for correspondence: Dr S Pearce, 9 Almoners Barn, Durham DH1 3TZ.

Email: sarahpearce2@gmail.com 